\title{
ANGULAR VELOCITY AND CONTACT FORCE SIMULATION OF THE SPIRAL BEVEL GEAR MESHING BASED ON THE HERTZ CONTACT THEORY
}

\author{
Lizhi Gu ${ }^{1 *}$ - Tieming Xiang ${ }^{1,2}$ - Can Zhao ${ }^{1}$ - Shuailiang Guo ${ }^{1}$
}

${ }^{1}$ College of Mechanical Engineering and Automation, Huaqiao University, Xiamen, 361021, China

${ }^{2}$ School of Mechanical \& Automotive Engineering, Xiamen University of Technology, Xiamen, 361024, China

\begin{tabular}{l} 
ARTICLE INFO \\
\hline Article history: \\
Received: 26.8 .2016$. \\
Received in revised form: 3.1 .2017$. \\
Accepted: 22.2 .2017$. \\
\hline Keywords: \\
Spiral bevel gear \\
Angular velocity \\
Tangential component of contact force \\
NURBS \\
Hertz contact theory \\
Tooth flank equation \\
\hline
\end{tabular}

DOI: http://doi.org/10.30765/er.39.2.4

\begin{abstract}
:
To obtain the change tendency of the wheel's angular velocity and tangential component of contact force with time of the pinion under the step input during spiral bevel gear meshing, the tooth flank equation of spiral bevel gear was constructed based on the Non-Uniform Rational B-splines curve. The three-dimensional model of the pinion and the wheel were built based on the tooth flank equation. The calculation equation and relative parameters set for the contact force of spiral bevel gear meshing were done based on the Hertz contact theory. A mating of spiral bevel gears was taken as an example for dynamics simulation and the simulation results show that the relative error rate of the angular velocity between simulation and theoretical calculation is $0.054 \%$, and that the relative error rate of tangential component of the contact force between simulation and theoretical calculation is $4.82 \%$. These findings provide the theoretical basis for dynamic characteristics optimization of the spiral bevel gears.
\end{abstract}

specialists did extensive researches on this topic. Among them Litvin F.L. made use of numerical analysis based on the local synthesis method of tooth contact analysis to study the meshing contact problem of the spiral bevel gear at University of Illinois in Chicago, USA [7]. Fong Z.H. proposed a four order comprehensive mathematical modeling curve for the spiral bevel gear tooth surface meshing at National Chung Cheng University in Taiwan of China [8]. Yao L.G. built the mathematical modeling and did the simulation for the external and internal double circular-arc spiral bevel gears at Fuzhou University in China [9]. Velex P. did the dynamic simulation of eccentricity errors in planetary gears at University of DeLyon in France

\footnotetext{
${ }^{*}$ Corresponding author. Tel.: +86-13110705113; fax: +86-0592-6291386

E-mail address: gulizhi8882@163.com
} 
[10]. Chen Z.G. did the dynamic simulation for the spur gear and planetary gear with tooth root crack propagating along a tooth width and crack depth at Chongqing University in China. [11-12]. Osman T. and Velex P. built a simulation model of the interactions between dynamic tooth loads and contact fatigue on the spur gears at University of DeLyon in France [13]. Jiang H.J. studied the dynamic characteristics of helical gears under sliding friction with spalling defect at Chongqing University in China [14]. Fang Z.D. proposed a precise modeling method of arc tooth face-gear with transition curve and did the motion analysis and finished the $\mathrm{NC}$ machining for the prototype at the Northwestern Polytechnic University in China [15]. Benamar F. used the kinematics approach to do the quasi-static motion simulation and slip prediction of articulated planetary rovers in France [16]. Simon V. V. finished the manufacture of optimized facehobbed spiral bevel gears on a computer numerical control hypoid generator at Budapest University of Technology and Economics in Hungary [17].

The ADAMS software package has been in a dominant position in the field of gear dynamics simulation research by using the commercial software method. Liu T. built the model of straight bevel gear by using the CATIA software package and finished the kinematics simulation by using IMPACT function for the calculation of Hertz contact force in the ADAMS software package [18]. Wang H.B. finished the dynamic simulation and fatigue reliability analysis of the straight bevel gear by using Pro/E and ADAMS [19]. Zeng H. did the dynamics simulation of the spiral bevel gear transmission system, and got the change curve of angular velocity and meshing force for the driven wheel by using the Pro/E and ADAMS commercial software package, but he ignored the transmission error [20]. Wu L.X. used UG NX software package to simulate a pair of involutes cylindrical gear meshing [21], but the angular velocity of the driven gear was determined by specified transmission ratio, so the angular velocity of driven gear is only the theoretical calculation value, which didn't expose the real condition of the gear meshing. The dynamic simulation of the angular velocity and contact force by using three-dimensional(3D) contact for a pair of the spiral bevel gears which were installed on the main reducer (also called differential gear) of a mini bus was done based on the Hertz contact theory. All these provide the basis for dynamic characteristics and optimization of the spiral bevel gear meshing.

\section{3D modeling of the spiral bevel gear}

\subsection{The NURBS tooth flank equation}

The correct meshing condition for a mating pair of gears needs to satisfy the Eq. (1) according to the Willis theory [22-23].

$$
\mathbf{v} \cdot \mathbf{n}=\mathbf{0}
$$

where $\mathbf{v}$ is the relative speed at the meshing contact point of the two gears, $\mathbf{n}$ is the normal vector of the meshing contact surface.

Vectors $\mathbf{v}$ and $\mathbf{n}$ are perpendicular to each other in the Eq. (1).

Based on the surface equation of a cutter disc [1], the tooth enveloping surface and meshing equation are obtained in terms of vectors through the coordinate transformation from the cutter coordinates to the coordinate system of semifinished product for the wheel.

$$
\left\{\begin{array}{l}
\mathbf{r}_{1}=\mathbf{M}_{1 \mathrm{t}} \cdot \mathbf{r}\left(u_{\mathrm{g}}, \theta_{\mathrm{g}}\right) \\
\mathbf{n} \cdot \mathbf{v}=\mathbf{f}\left(u_{\mathrm{g}}, \theta_{\mathrm{g}}, t\right)=\mathbf{0}
\end{array}\right.
$$

where $\mathbf{r}\left(u_{\mathrm{g}}, \theta_{\mathrm{g}}\right)$ is the curved surface of a cutter head; $\mathbf{M}_{1 \mathrm{t}}$ is the coordinate transformation matrix from the cutter coordinates to the coordinate system of semi-finished product of the wheel.

The discrete data coordinate values on the tooth surface of the spiral bevel gear can be calculated as shown in the Eq. (3) in the coordinate system of semi-finished product of the wheel by using the Eq. (2).

$$
S=R\left(u_{\mathrm{g}}, \theta_{\mathrm{g}}\right)
$$

The tooth profile tooth flank equation of the spiral bevel gear can be reconstructed by using the nonuniform rational B-spline (NURBS) curve surface function to fit the discrete data points that may be calculated with the Eq. (3) as data shape points. The tooth profile can be written in the following expression. 


$$
\begin{aligned}
& S(u, v)=\frac{\sum_{\mathrm{i}=0}^{m} \sum_{\mathrm{j}=0}^{n} W_{\mathrm{ij}} P_{\mathrm{ij}} N_{\mathrm{i}, \mathrm{k}}(u) N_{\mathrm{j}, 1}(v)}{\sum_{\mathrm{i}=0}^{m} \sum_{\mathrm{j}=0}^{n} W_{\mathrm{ij}} N_{\mathrm{i}, \mathrm{k}}(u) N_{\mathrm{j}, 1}(v)} \\
& u, v \in[0,1]
\end{aligned}
$$

where $W_{\mathrm{ij}}$ is the weight factor of the corresponding control points; $P_{\mathrm{ij}}$ is the grid control point column of the grid feature; $N_{\mathrm{i}, \mathrm{k}}(u)$ and $N_{\mathrm{j}, 1}(v)$ are B-spline basis functions of $\mathrm{k}$ order and 1 order respectively, which is defined by the node vector $\mathbf{S}=\left\{s_{0}, s_{1}, \cdots, s_{\mathrm{m}+\mathrm{k}+1}\right\} \quad$ and the node vector $\mathbf{T}=\left\{t_{0}, t_{1}, \cdots, t_{\mathrm{m}+\mathrm{k}+1}\right\}$, respectively.

$$
R_{\mathrm{ij}}(u, v)=\frac{W_{\mathrm{ij}} N_{\mathrm{i}}, k(u) N_{\mathrm{j}}, l(v)}{\sum_{x=0}^{m} \sum_{y=0}^{n} W_{\mathrm{xy}} N_{\mathrm{x}}, k(u) N_{\mathrm{y}}, l(v)}
$$

where $R_{\mathrm{ij}}(\mathrm{u}, \mathrm{v})$ is the piecewise rational basis function expression of NURBS surface.

Suppose node vectors $\mathbf{S}=\left\{s_{0}, s_{1}, \cdots, s_{\mathrm{m}+\mathrm{k}+1}\right\}$ and $\mathbf{T}=\left\{t_{0}, t_{1}, \cdots, t_{\mathrm{m}+\mathrm{k}+1}\right\}$ which are defined on the nonuniform parameter axis can be expressed as following, respectively.

$$
\begin{aligned}
& \mathbf{S}=\{\underbrace{0,0, \cdots 0}_{\mathrm{k}+1}, \mathrm{~s}_{\mathrm{k}+1} \cdots, \mathrm{s}_{\mathrm{m}+\mathrm{p}-1}, \underbrace{1,1, \cdots 1}_{\mathrm{k}+1}\} \\
& \mathbf{T}=\{\underbrace{0,0, \cdots 0,}_{1+1} \mathrm{t}_{\mathrm{l}+1} \cdots, t_{\mathrm{n}+1-1}, \underbrace{1,1, \cdots 1}_{1+1}\}
\end{aligned}
$$

The surface defined by the node vector $\mathbf{S}=\left\{s_{0}, s_{1}, \cdots, s_{\mathrm{m}+\mathrm{k}+1}\right\}$ and $\mathbf{T}=\left\{t_{0}, t_{1}, \cdots, t_{\mathrm{m}+\mathrm{k}+1}\right\}$ are non-uniform, non-periodic rational B-spline surfaces, also called the NURBS surface.

The dual three order NURBS tooth flank equation [2] of the tooth profile surface for spiral bevel gear was derived according to the Eq. (4), and it can be written as Eq. (7) when $\mathrm{k}=\mathrm{l}=3$.

$$
s(u, v)=\frac{\sum_{\mathrm{k}=0}^{3} \sum_{\mathrm{l}=0}^{3} W_{\mathrm{i}+\mathrm{k}, \mathrm{j}+1} P_{\mathrm{i}+\mathrm{k}, \mathrm{j}+\mathrm{l}} N_{\mathrm{i}+\mathrm{k}}, 3(u) N_{\mathrm{j}+\mathrm{l},} 3(v)}{\sum_{\mathrm{k}=0}^{3} \sum_{\mathrm{l}=0}^{3} W_{\mathrm{i}+\mathrm{k}, \mathrm{j}+1} N_{\mathrm{i}+\mathrm{k},} 3(u) N_{\mathrm{j}+1} 3(v)}
$$

$$
\begin{gathered}
(\mathrm{i}=0,1, \cdots, m)(\mathrm{j}=0,1, \cdots, \mathrm{n}) \\
u, v \in[0,1]
\end{gathered}
$$

\subsection{Some parameters of a mating pair of the spiral bevel gears}

Some parameters are shown in Table 1 for a pair of spiral bevel gear which was installed on the main reducer (also called differential gear) of a mini bus.

Table 1. Some parameters of a mating pair of the spiral bevel gears

\begin{tabular}{|c|c|c|c|}
\hline Parameters & Symbol & Pinion & Wheel \\
\hline Number of teeth & $\mathrm{z}$ & 9 & 37 \\
\hline Modulus & $\mathrm{m} / \mathrm{mm}$ & 4.5 & 4.5 \\
\hline Pitch cone angle & $\delta /\left(^{\circ}\right)$ & 13.671 & 76.329 \\
\hline Shaft angle & $\sum /\left(^{\circ}\right)$ & 90 & 90 \\
\hline $\begin{array}{c}\text { Pitch circle } \\
\text { diameter }\end{array}$ & $\mathrm{d} / \mathrm{mm}$ & 40.5 & 166.5 \\
\hline Pressure angle & $\alpha_{\mathrm{n}} /\left(^{\circ}\right)$ & 20 & 20 \\
\hline Spiral angle & $\beta_{\mathrm{m}} /\left(^{\circ}\right)$ & 35 & 35 \\
\hline
\end{tabular}

\subsection{The NURBS curve fitting and surface reconstruction}

Fit the NURBS curve by the function of a curve fitting according to the Eq. (6) and the relevant parameters in the Table 1. Reconstruct the NURBS fitting tooth surface by the curve mesh function through choosing the primary strings line (U line) and the cross strings line (V line) respectively.

\subsection{The model construction of a pair of the spiral bevel gear}

Generate the 3D solid model from the 3D slice model according to the NURBS tooth profile surface, then detail repair should be done according to the actual situation, such as hollow a hole on semi-finished product of the wheel for the installment of a differential. Build the 3D model of the pinion and the wheel respectively. There are three constraint conditions according to the actual situation during the assembly process between the pinion and the wheel. That includes the shaft angle $\sum$ being equal to 90 degrees, the pitch cone vertices of the pinion, and the wheel that are coincident and contact aligned on the tooth surface of the pitch circle of the exterior transverse. Finally, the 3D 
model was constructed as shown in Fig. 1 after the assembly was done.

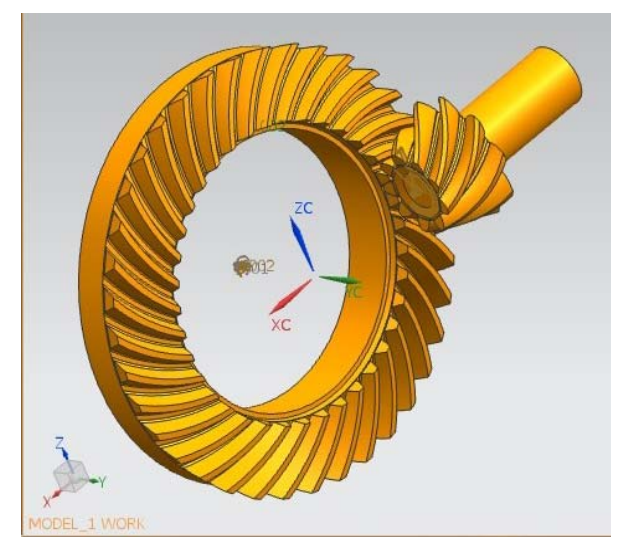

Figure 1. 3D assembly model of a mating pair of the spiral bevel gears.

\section{The simulation of angular velocity and contact force}

\subsection{The calculation formula of contact force}

Based on the Hertz contact theory, the calculation formula of the contact force can be written as the Eq. (8).

$$
\mathbf{F}=k x^{e}+\operatorname{Step}(x, 0,0, d, C) \dot{x}
$$

where $\mathbf{F}$ is the contact force; $k$ is the contact stiffness; $\boldsymbol{x}$ is the penetration depth of contact, $x<0$ means contact occurs, otherwise there is no contact; $e$ is the index of contact force; $\operatorname{Step}(x, 0,0, d, C)$ is the step function; $C$ is the damping coefficient and $d$ is the maximum penetration depth of contact.

The calculation formula of the contact stiffness $k$ can be written in terms of

$$
k=\frac{4}{3} \sqrt{\frac{R_{1} R_{2}}{R_{1}+R_{2}}} \times \frac{\alpha E_{1} E_{2}}{E_{1}\left(1-v_{2}^{2}\right)+E_{2}\left(1-v_{1}^{2}\right)}
$$

where $R_{1}$ and $R_{2}$ are the corresponding equivalent radius at two gears meshing contact points, respectively. Use exterior transverse pitch circle radius of the spiral bevel gear to replace $R_{1}$ and $R_{2}$ respectively; $\alpha$ is the correction coefficient, the range of $\alpha$ is from 0.5 to $1.0 ; v_{1}$ and $v_{2}$ are the Poisson's ratio of two kinds of contact material respectively; $E_{1}$ and $E_{2}$ are the elastic modulus of two kinds of contact materials, respectively. The materials of the pinion and the wheel are both C45 steel (DIN specification). So $v_{1}=v_{2}=0.285$ and $E_{1}=$ $E_{2}=2.07 \times 105 \mathrm{~N} / \mathrm{mm}^{2}$. The contact stiffness $k=6.65 \times 10^{7}$ can be calculated according to the Eq. (8) and (9). The index of the contact force $e$ is 1.5 , the damping coefficient $C$ is $50 \mathrm{~N} \cdot \mathrm{s} / \mathrm{mm}$, the maximum penetration depth $d$ is $0.1 \mathrm{~mm}$, the static friction coefficient is 0.08 and the dynamic friction coefficient is 0.05 according to literatures [24-27].

\subsection{Setting of the simulation environment}

The flow chart of dynamics simulation is shown in Fig. 2. Establish the dynamic simulation tasks in the Motion module of the UG NX software package according to the flow chart. Create the links for the pinion and the wheel of the spiral bevel gear respectively and add the corresponding rotation joints around the rotation center axis of the pinion and the wheel. Use the 3D contact to simulate the contact condition between the contact surface of the pinion and the wheel. Put the relevant parameters for calculating the contact force into corresponding blank of 3D contact dialog box. Carrying the simulation can get the contact force and contact motion between the pinion and the wheel.



Figure 2. The simulation flow chart. 
In order to avoid the transilience caused by the impact from the rotational angular speed of the pinion, the way of adding load for angular velocity on the pinion is the step function. The angular velocity of the pinion is 7703 degrees per second, and the load of the wheel torque is $1964.99 \mathrm{Nm}$, which is the engine torque through the transmission and main reducer (also called differential gear) of the mini bus. The simulation time is set for one second and the simulation steps are set for 500 steps. The simulation results are shown from Fig. 3 to Fig. 8.

The change curve of input angular velocity versus time for the pinion is shown in Fig. 3. The load of the angular velocity on the pinion is a step function, where a linear increases gradually before 0.2 seconds and maintains stability at 7703 degrees per second approximately after 0.2 seconds.

\subsection{The angular velocity simulation of the wheel}

The simulation results of the wheel's angular velocity by using 3D contact force simulation based on the Hertz contact theory is shown in Fig. 4. It can be seen that the angular velocity of the wheel is increasing with time close to the linear relation before 0.2 seconds and then tends to be stable, but it still fluctuates based on the stable value after

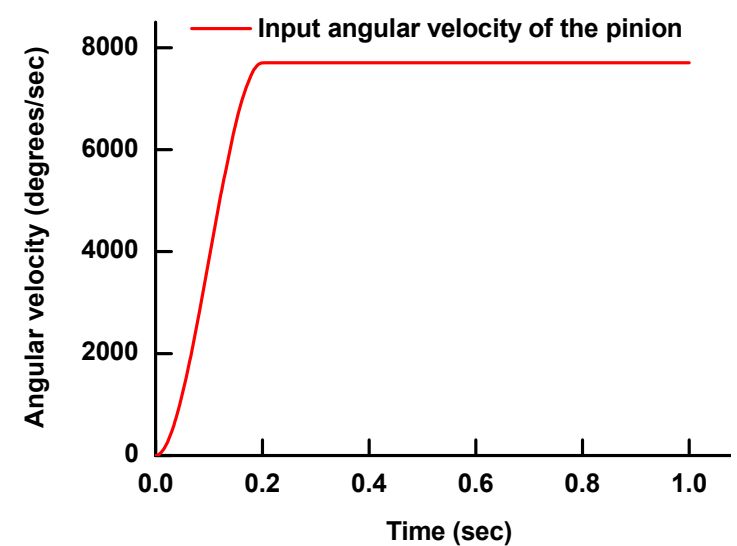

Figure 3. The input angular velocity of the pinion.

0.2 seconds. The average value of the wheel's angular velocity is 1872.69 degrees per second calculated by the simulation data from 0.2 seconds to 1.0 seconds.

The theoretical calculation formula of the wheel's angular velocity can be written as follows.

$$
n_{2}=n_{1} \times z_{1} / z_{2}
$$

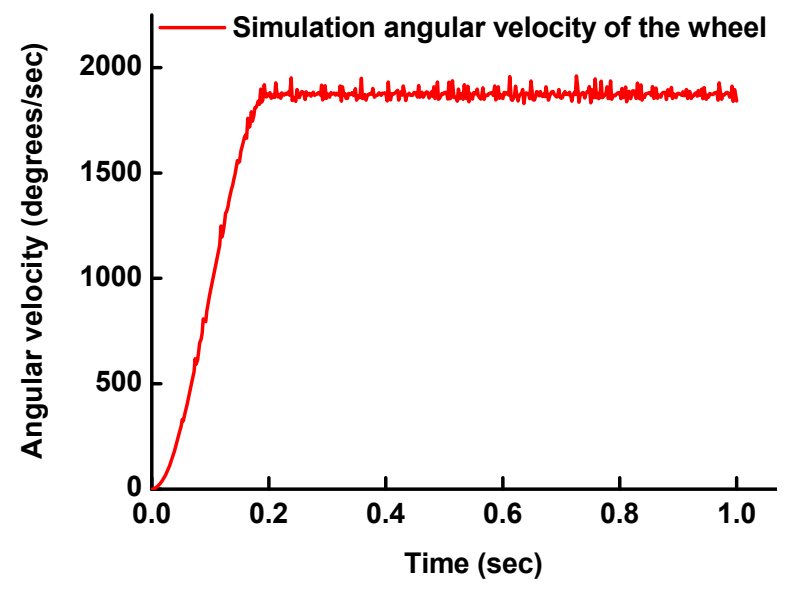

Figure 4. Angular velocity simulation of the wheel.

where $n_{2}$ is the theoretical calculation value of the output angular velocity for the wheel; $n_{1}$ is the input angular velocity of the pinion; $z_{1}$ is the pinion's tooth number, and $z_{2}$ is the wheel's tooth number.

Put the specific parameters into the Eq. (10) and one may get the theoretical calculation value of the wheel's angular velocity, say $n_{2}=1873.703$ degrees per second. Draw the wheel's angular velocity curve of theoretical calculation as shown in Fig. 5.

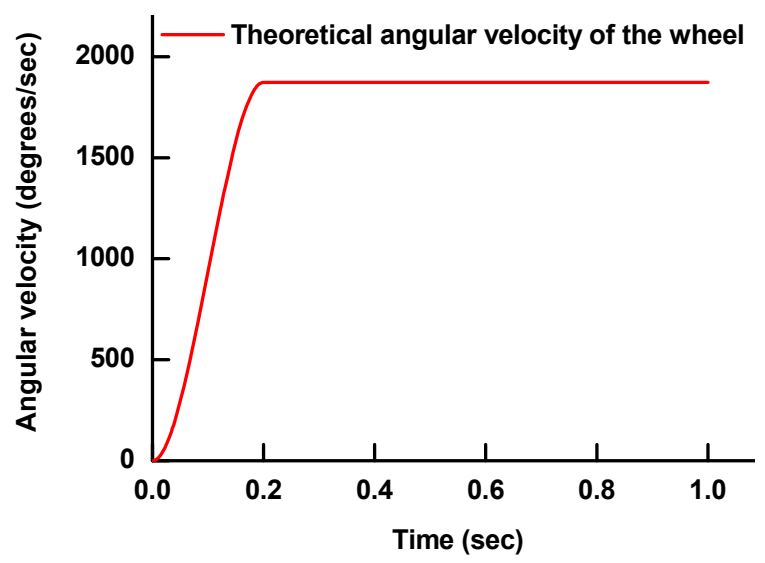

Figure 5. The theoretical angular velocity curve of the wheel.

Clone a new simulation task by using the UG gear pair instead the 3D contact in the UG NX software package. Set the number of teeth to 9 and 37 of the pinion and the wheel respectively and carry the UG gear pair simulation. The wheel's angular velocity can be calculated using the UG gear pair simulation of 1873.703 degrees per second after 0.2 seconds from the simulation data of the UG gear pair simulation. The angular velocity is a constant value after 0.2 seconds by using the UG gear pairs, without fluctuations, does not change with time, and 
it is completely consistent with the theoretical calculated value from the Eq. (10).

Add Fig. 4 and Fig. 5 together. There is Fig. 6 for the sake of comparison.

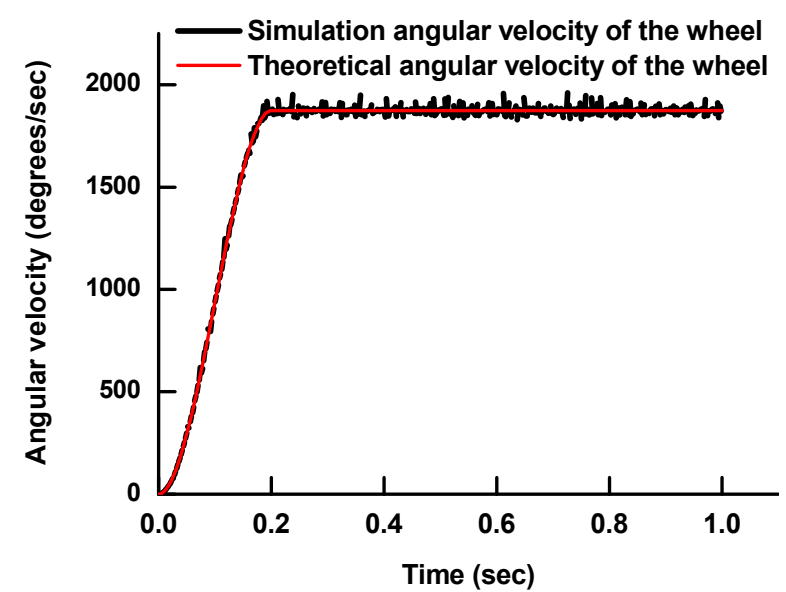

Figure 6. The comparison between the simulation angular velocity and the theoretical angular velocity.

It can be seen that the angular velocity simulation by using $3 \mathrm{D}$ contact for the wheel is close to the angular velocity curve of the theoretical calculation. However, the simulation angular velocity of $3 \mathrm{D}$ contact fluctuates up and down nearby the angular velocity curve of the theoretical calculation. In order to reflect the difference of the angular velocity between $3 \mathrm{D}$ contact simulation and the theoretical calculation more clearly, we used the curve in Fig. 4 to subtract the curve in Fig. 5. Furthermore, the absolute value was retaken and the wave amplitude curve was accomplished as shown in Fig. 7. It can be seen that the simulation angular velocity of $3 \mathrm{D}$ contact for the wheel is close to the theoretical calculation curve and that it fluctuates up and down. The average amplitude value of the fluctuations is 13.5 degrees per second. The maximum amplitude value reach to 86.9 degrees per second.

\subsection{The simulation of the tangential component of contact force for the wheel}

Extract the tangential component of contact force from the contact force data during the spiral bevel gear meshing. The amplitude change curve of contact. The force tangential component versus time is shown in Fig. 8. The average value of the tangential component of contact force during the spiral bevel gear meshing is $24799.9 \mathrm{~N}$ and the maximum value is $26498.9 \mathrm{~N}$.

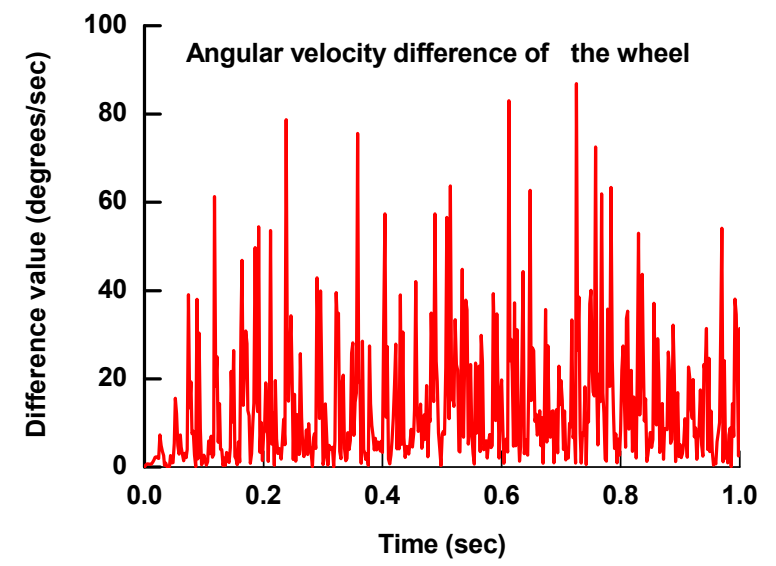

Figure 7. The difference curve between the simulation and the theoretical calculation.

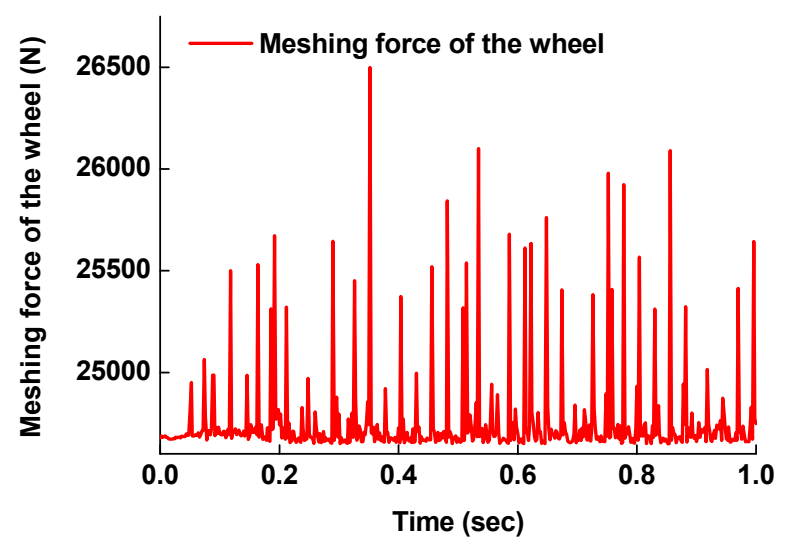

Figure 8. The change curve of the tangential component of contact force.

In order to reflect the simulation value change magnitude of the tangential component of contact force more clearly, use the simulation value of the tangential component of contact force to subtract the simulation average value of the tangential component of contact force. Furthermore, retake the absolute value, and get the wave amplitude curve as shown in Fig. 9. The average fluctuations magnitude of the tangential component of contact force for the spiral bevel gear meshing is $117.53 \mathrm{~N}$ and the maximum amplitude value is $1741.3 \mathrm{~N}$.

In order to verify the correctness of the simulation result for the tangential component of contact force, the theoretical calculation formula of the tangential component of contact force is used to calculate the theoretical calculation value directly, which can be written in terms of

$$
\mathbf{F}=\frac{2 \mathbf{T}}{d}
$$




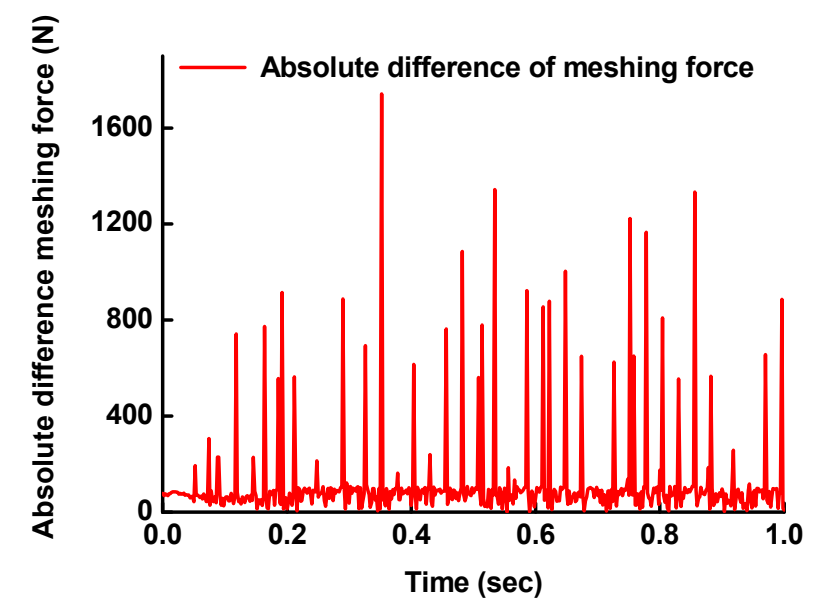

Figure 9. The absolute difference charge curve of the tangential component of contact force.

where $\boldsymbol{F}$ is the tangential component of contact force of the wheel; $\boldsymbol{T}$ is the transmission torque of the wheel, and $d$ is the pitch circle diameter of the wheel.

Put the relative parameter value into the Eq. (11) can get $F=23603.48 \mathrm{~N}$.

The comparison between simulation and theoretical calculation of the angular velocity and the tangential component of contact force for the wheel is shown in Table 2.

The result of the relative error rate for the wheel's angular velocity simulation is $0.054 \%$. The fact that the relative error rate is so small indicates that the simulation model for the angular velocity simulation is of rational.

As a matter of fact, the pinion and the wheel are indeed rotating around its rotation axis respectively according to the rule of their contact during the 3D contact simulation.

The phenomenon of a tooth surface infiltration and embedding interference don't happen, the wheel rotated no more or less a circle or even a tooth during the entire meshing, while the small fluctuations of the angular velocity exist. There is some difference in the angular velocity between simulation and theoretical calculation because of the fluctuations.

The result of the relative error rate for the wheel's tangential component of contact force is $4.82 \%$, which is within the error range of engineering allowable if is no more than 5\%. There are many reasons for this result. The theoretical calculation value is not the real value during the actual meshing.
Table 2. The comparison between the simulation and the theoretical calculation

\begin{tabular}{|c|c|c|}
\hline Items & $\begin{array}{c}\text { Angular } \\
\text { velocity }\end{array}$ & $\begin{array}{c}\text { Tangential } \\
\text { component of } \\
\text { contact force }\end{array}$ \\
\hline Unit & $\% / \mathrm{s}$ & $\mathrm{N}$ \\
\hline $\begin{array}{c}\text { Average of } \\
\text { simulation value }\end{array}$ & 1872.69 & 24799.9 \\
\hline Theoretical value & 1873.70 & 23603.5 \\
\hline Difference & 1.01 & 1196.4 \\
\hline $\begin{array}{c}\text { Relative error } \\
\text { rate }\end{array}$ & $0.054 \%$ & $4.82 \%$ \\
\hline
\end{tabular}

This is because the theoretical calculation formula has done some simplification for the model and it has ignored some factors such as the contact point which is defined on the pitch circle of the exterior transverse while the real contact condition is not. There must be some errors for the simulation result of the tangential component of contact force because of the different setting value of the stiffness coefficient, index of contact force, damping coefficient, and friction coefficient, etc. A way to reduce the relative error rate between simulation and theoretical calculation is by changing the value of relative parameters in order to satisfy the theoretical calculation value before the simulation.

\section{Conclusion}

(1) The spiral bevel gear tooth surface model was reconstructed by using the double three orders NURBS surface fitting of the meshing point based on the meshing equation. The $3 \mathrm{D}$ assembly model was also established for the mechanism consisting of a mating pair of the spiral bevel gears.

(2) The contact force calculation formula of the 3D contact based on the Hertz contact theory was derived with the relative parameters in the calculation formula of contact force for the spiral bevel gear meshing simulation.

(3) The simulation of the angular velocity and the tangential component of contact force for the wheel of the spiral bevel gear meshing was done respectively. The simulation relative error rate of the wheel's angular velocity between the simulation and the theoretical calculation is $0.054 \%$. The simulation relative error rate of the wheel's tangential component of contact force between simulation and 
theoretical calculation is $4.82 \%$, which is still within the error limitation of engineering allowance.

\section{Acknowledgments}

This work is supported by Natural Science Foundation of China under grant No. 51475399, No. 51375411 and the Science and Technology Projects of Fujian Province of China under No. JA14240, No.2014H0049 and Fujian Science and Technology Platform Project of China grant No. 2016H2003.

\section{Reference}

[1] Tang, J.Y., Pu, T.P.: FEM numerical analysis of the dynamic engagement of spiral bevel gears, Mechanical Science and Technology for Aerospace Engineering, 28(2009), 8, 981985.

[2] Huang, Z.H, Zhang, X.J. and Zhou, Y.J.: Simulation of contact force of involute gear meshing, Journal of Central South University (Science and Technology), 42(2011), 2, 379383.

[3] Bi, F.R., Cui, X.T. and Liu, N.: Computer simulation for dynamic meshing force of Involute gears, Journal of Tianjin University, 38 (2005), 11, 991 - 995.

[4] Lu, S.Q.: Theory and simulation analysis of Multi-variable gear pump gear contact force, Journal of Hydraulic and Pneumatic, 37(2014), 2, 101-104.

[5] Tang, J.Y. and Pu, T.P.: A study of contact path variation of a loaded spiral bevel gear, Mechanical Science and Technology, 29(2010), 4, 461-466.

[6] Li, M. and Hu, H.Y.: Dynamic analysis of a spiral bevel-geared rotor-bearing system, Journal of Sound and Vibration, 259(2003), 3, 605-624.

[7] Litvin, F.L., Donno, M.D. and Peng, A. et al.: Integrated computer program for simulation of meshing and contact of gear drives. Computer Methods in Applied Mechanics and Engineering, 181(2000), 2, 71-85.

[8] Wang, P.Y. and Fong, Z.H.: Fourth-Order Kinematic Synthesis for Face-Milling Spiral Bevel Gears with Modified Radial Motion(MRM) Correction. Journal of Mechanical Design(ASME), 128(2006), 3, 457-467.

[9] Yao, L.G., Gu, B., Huang, S.J. et al.:
Mathematical Modeling and Simulation of the External and Internal Double Circular-Arc Spiral Bevel Gears for the Nutation Drive, Journal of Mechanical Design(ASME), 132(2010),2,021008, pp1-10.

[10] $\mathrm{Gu}, \mathrm{X}$. and Velex, P.: On the dynamic simulation of eccentricity errors in planetary gears, Mechanism and Machine Theory, 61(2013), 1, 14-29.

[11] Chen, Z.G., Shao, Y.M. and Su, D.Z.: Dynamic simulation of planetary gear set with flexible spur ring gear, Journal of Sound and Vibration. 332(2013), 26, 7191-7204.

[12] Chen, Z.G. and Shao, Y.M.:Dynamic simulation of planetary gear with tooth root crack in ring gear, Engineering Failure Analysis, 31(2013), 7, 8-18.

[13] Osman, T. and Velex, P. A model for the simulation of the interactions between dynamic tooth loads and contact fatigue in spur gears, Tribology International, 46(2012), 1, 84-96.

[14] Jiang, H.J., Shao, Y.M. and Mechefske, C.K.: Dynamic characteristics of helical gears under sliding friction with spalling defect. Engineering Failure Analysis, 39(2014), 4, 92-107.

[15] Cui, Y.M., Fang, Z.D. and Su, J.Z. et al. : Precise modeling of arc tooth face-gear with transition curve, Chinese Journal of Aeronautics, 26(2013), 5, 1346-1351.

[16] Benamar, F. and Grand, C.: Quasi-Static Motion Simulation and Slip Prediction of Articulated Planetary Rovers Using a Kinematic Approach, Journal of Mechanisms and Robotics(ASME), 5(2013), 3, 021002, pp1-13.

[17] Simon, V.V.: Manufacture of Optimized Face-Hobbed Spiral Bevel Gears on Computer Numerical Control Hypoid Generator, Journal of Manufacturing Science and Engineering(ASME), 136(2014), 6, 031008, pp1-9.

[18] Liu, T., Yu, H.D. and Li, Y.Q. et al.: Modeling and dynamic simulation of straight bevel gear based on CATIA and ADAMS, Journal of Mechanical Transmission, 34(2010), 3, 109-112.

[19] Wang, H.B., Ma, S.P. and Wang, H.G.: Study on dynamic characteristics and fatigue analysis about gear transmission based on ADAMS, Machine Tool \& Hydraulic, 
35(2007), 12, 180-182.

[20] Zeng, H., Zhang, W.G. and Li, Y.: Dynamics simulation of spiral bevel gear transmission based on ADAMS, Machinery Design \& Manufacturing, 34(2011), 3, 71-72.

[21] Wu, L.X.: Research of parametrized design of gear and movement emulation analysis based on UG, Beijing University of Posts and Telecommunications, College of automation, Beijing, China, 2009.

[22] Litvin, F.L.:Gear geometry and applied theory. Prentice hall Englewood cliffs New Jersey Press, New Jersey, 1994.

[23] Litvin, F.L. and Alfonso, F.: Gear geometry and applied theory (Second Edition). Cambridge University Press, New York, 2004.

[24] Wan, Z.G., Cao, H.R. and Zi, Y.Y. et al.: An improved time-varying mesh stiffness algorithm and dynamic modeling of gearrotor system with tooth root crack, Engineering Failure Analysis, 42(2014), 7, 157-177.

[25] Lin, T.J., Ou, H. and Li, R.F. et al. : A finite element method for $3 D$ static and dynamic contact impact analysis of gear drives, Comput. Methods Appl. Mech. Engrg, 196(2007), 9, 1716-1728.

[26] Sharma, C., Dwivedi, D.K. and Kumar, P.: Influences of friction stir welding on the microstructure, mechanical and corrosion behaviour of $\mathrm{Al}-\mathrm{Zn}-\mathrm{Mg}$ aluminium alloy 7039, Engineering Review, 35(2015), 3, 267274.

[27] Zhang, D.: Constrained robust model predictive control for time-delay descriptor systems with linear fractional uncertainty, Engineering Review, 35(2015), 2, 147-155. 